\title{
A Rare Case of Celiac Artery Compression Syndrome/MAL Syndrome
}

\author{
Ram Kumar Raghuwanshi ${ }^{1}$, Arvind Ghanghoria ${ }^{2}$
}

1Department of General Surgery, MGM Medical College, Indore, Madhya Pradesh, India.

2 Department of General Surgery, MGM Medical College, Indore, Madhya Pradesh, India.

\section{INTRODUCTION}

Celiac artery compression syndrome also known as median arcuate ligament syndrome/dunbar syndrome/celiac axis syndrome is a rare cause of abdominal pain and weight loss. It is caused by compression of the celiac artery and possibly the celiac ganglion by the median arcuate ligament.[1] Median arcuate ligament crosses in front of the celiac artery in approximately $10-24 \%$ of the normal asymptomatic patients, but severe compression is seen in only $1 \%$ of the patients associated with symptoms of median arcuate ligament syndrome (MALS).[1],[2]

\section{PRESENTATION OF CASE}

A 24-year-old female presented with complaints of abdominal pain, anorexia, nausea since 3 years. Pain got aggravated on taking meals, supine position, straining, deep inspiration and sometimes associated with nausea and relieved on walking and sitting position. Pain was sharp and constant. Weight loss of $10 \mathrm{Kg}$ reported since last 2-3 years. CECT abdomen of the patient was done which showed short segment severe narrowing at the origin of celiac artery with post stenotic dilatation (figure-1)

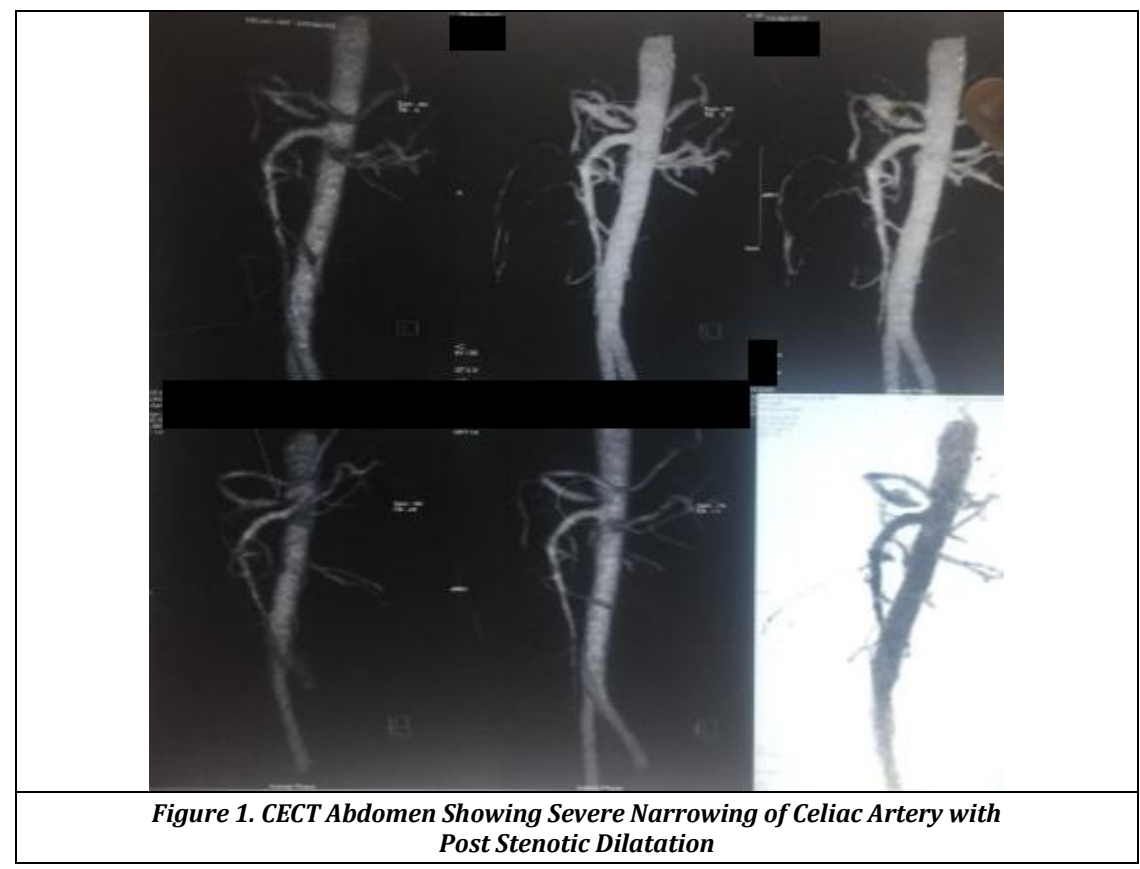

\section{DISCUSSION OF MANAGEMENT}

Exploratory laparotomy of the patient was planned with careful dissection celiac trunk was exposed. Median arcuate ligament was subsequently divided that results in bulging of celiac artery indicating release of compression over celiac artery. Patient was followed after 3 months. Postoperatively, her pain and other complaints were resolved and she started gaining weight too.
Corresponding Author:

Ram Kumar Raghuwanshi, \#280, Singapore Township, Near ICICI ATM, Indore-453771, Madhya Pradesh, India.

E-mail:ram.nscb@gmail.com

DOI: $10.14260 / \mathrm{jemds} / 2019 / 786$

Financial or Other Competing Interests: None.

How to Cite This Article:

Raghuwanshi RK, Ghanghoria A. A rare case of celiac artery compression syndrome/MAL syndrome. J. Evolution Med. Dent. Sci. 2019;8(48):3641-3642, DOI: $10.14260 / \mathrm{jemds} / 2019 / 786$

Submission 24-09-2019,

Peer Review 14-11-2019,

Acceptance 20-11-2019,

Published 02-12-2019. 


\section{DISCUSSION}

Celiac artery compression syndrome is a very rare condition. It occurs due to focal stenosis of the celiac artery which is caused by compression by the median arcuate ligament. This stenosis may arise either due to abnormal inferior insertion of the diaphragmatic crura or celiac artery originating superiorly.[3] Celiac artery compression syndrome occurring in several members of the same family and in monozygotic twins which shows that congenital factor might play a role in its development.[4],[5]

It is a diagnosis of exclusion. Patients suffering with this syndrome undergo extensive workup for other causes of abdominal pain and gastrointestinal reflux disease.[6] These patients might be operated for unnecessary cholecystectomies and appendectomies to get rid of the pain. Doppler ultrasound, MR angiogram, and CT angiogram are used for the diagnosis of the patients suffering from this syndrome..[1] However, CT angiogram remains the gold standard for the diagnosis. Surgical division of the fibers of the median arcuate ligament (Figure-2) either by open surgery or by laparoscopic approach is usually seems to be sufficient in most of the patients for getting rid of the debilitating symptoms.[7] The other modalities of treatment that can be tried include celiac artery bypass surgery, stent placement and transluminal dilation.[8]

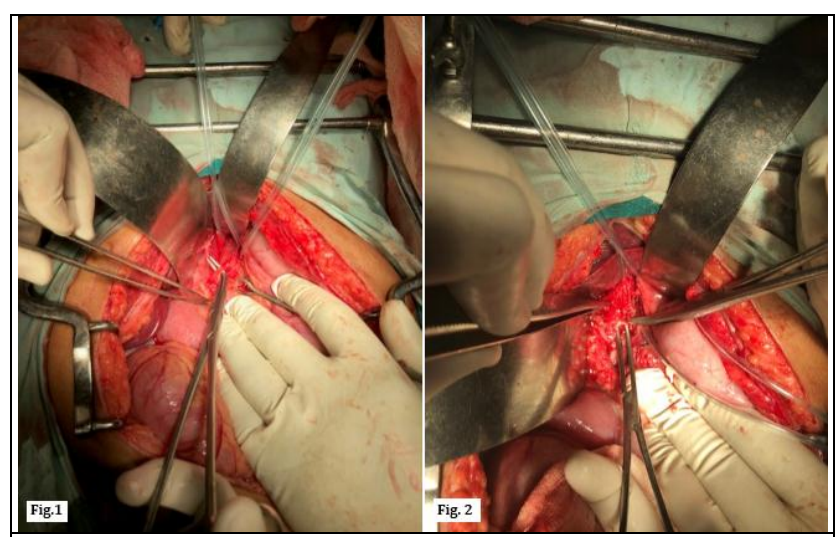

Figure 2 \& 3. Showing Division of Fibers of Median Arcuate Ligament

\section{CONCLUSIONS}

Celiac artery compression syndrome remains a clinical diagnosis with symptoms varying from no symptoms to debilitating symptoms which depends on development of collaterals. The aetiology of celiac artery compression syndrome is most accurately diagnosed by CT angiography which demonstrate both intraluminal and extraluminal causes as well as collateral flow to the proximal small bowel and liver. Good long-term prognosis is seen in three fourth of the patients after the surgical division of the median arcuate ligament.

\section{REFERENCES}

[1] Horton KM, Talamini MA, Fishman EK. Median arcuate ligament syndrome: evaluation with CT angiography. Radiographics 2005;25(5):1177-82.

[2] Lindner HH, Kemprud E. A clinicoanatomical study of the arcuate ligament of the diaphragm. Arch Surg 1971;103(5):600-5.

[3] Dunbar JD, Molnar W, Beman FF, et al. Compression of the celiac trunk and abdominal angina. The American Journal of Roentgenology, Radium Therapy and Nuclear Medicine 1965;95(3):731-44.

[4] Okten RS, Kucukay F, Tola M, et al. Is celiac artery compression syndrome genetically inherited? A case series from a family and review of the literature. European Journal of Radiology 2012;81(6):1089-93.

[5] Bech F, Loesberg A, Rosenblum J, et al. Median arcuate ligament compression syndrome in monozygotic twins. Journal of Vascular Surgery 1994;19(5):934-8.

[6] Chou JW, Lin CM, Feng CL, et al. Celiac artery compression syndrome: an experience in a single institution in Taiwan. Gastroenterology Research and Practice 2012;2012:935721.

[7] Duncan AA. Median arcuate ligament syndrome. Curr Treat Options Cardiovasc Med 2008;10(2):112-6.

[8] Reilly LM, Ammar AD, Stoney RJ, et al. Late results following operative repair for celiac artery compression syndrome. J Vasc Surg 1985;2(1):79-91. 